REVISTA ANDALUZA DE ANTROPOLOGÍA.

NÚMERO 10: ANTROPOLOGÍA Y EPISTEMOLOGÍAS DEL SUR: EL RETO DE LA DESCOLONIZACIÓN DE LA PRODUCCIÓN DEL CONOCIMIENTO

MARZO DE 2016

ISSN 2174-6796

[pp. 143-166]

http://dx.doi.org/10.12795/RAA.2016.10.08

\title{
EN ECUADOR: DECOLONIALIDAD, POLÍTICA CULTURAL, Y UNIVERSIDAD DE LAS ARTES
}

\section{DECOLONIALISM, CULTURAL POLICY AND UNIVERSITY OF THE ARTS OF ECUADOR}

Lourdes Méndez

Universidad del País Vasco/Euskal Herriko Unibertsitatea

Resumen.

En Ecuador las nociones de decolonialidad, interculturalidad y Sumak Kawsay se han incorporado a los planes de política cultural diseñados desde 2007 por el Ministerio de Cultura. Esas nociones forman parte del léxico de quienes desean decolonizar la universidad, construir conocimientos in-disciplinados y crear una estética decolonial, y también de un gobierno populista post-neoliberal que las utiliza como consignas políticas enmascarando gracias a ellas los procesos neoliberales en curso en el país. A partir de datos obtenidos en Quito, Guayaquil y Loja entre 2012 y 2014, en este artículo analizaremos la reflexividad institucional existente entre diversos agentes académicos y políticos prestando especial atención a la creación de la Universidad de las Artes.

Palabras clave.

Decolonialidad, política cultural, estética decolonial, neoliberalismo, universidad de las artes. 


\begin{abstract}
.
The notions of decolonialism, interculturalism and Sumak Kawsay have been integrated into the cultural policies designed by Ecuador's Ministry of Culture since 2007. Those notions are part of the language of those who want to decolonialize the university, build un-disciplined knowledges and create a decolonial aesthetic, and are also utilised by a government populist post-neoliberal that uses them as political slogans that masks trough them the neoliberal processes that are taking place in the country. Based on data obtained in Quito, Guayaquil and Loja between 2012 and 2014 this article analizes the institutional reflexivity existing in diverse academic and political agents paying special attention to the creation of the University of the Arts.
\end{abstract}

\title{
Keywords.
}

Decolonialism, cultural policy, decolonial aesthetic, neoliberalism, University of the Arts

"Ante el cuestionamiento de su postura [Mignolo] terminó diciendo: 'nosotros tomamos café con los marxistas, pero no vamos más lejos'. Con esta frase [...] se desvela la posición antimarxista de los pregoneros de los estudios culturales, [...] que afincados en universidades norteamericanas y ahora en buena parte de algunas de las universidades en América Latina [...], pretenden atacarse al Capitalismo bajo una pretendida lucha de los excluidos y dominados de los grandes discursos generados en "Occidente" particularmente en Europa. [...] Sorprende que en una universidad creada y mantenida con dineros de la explotación colonial de recursos naturales por más de dos siglos, hoy se esté gestando un pensamiento decolonial. Esto es 'verdaderamente admirable y digno de tenerse en cuenta', diría un marxista luego de tomarse un café con un portavoz del decolonialismo cultural" (Arcos-Palma, 2010).

La universidad norteamericana a la que alude este teórico del arte colombiano es la de Duke, y una de las de América Latina en la que se han afincado los estudios culturales es la Universidad Andina Simón Bolívar (UASB) de Ecuador. El cuestionamiento de la postura de Mignolo, profesor en Duke, se produjo en Bogotá durante Estéticas Decoloniales evento "convocado para sentir, pensar y hacer, desde la Abya Yala y la Gran Comarca (que) empezó a gestarse [...] en 2009 entre Pedro Pablo Gómez, doctorando, y Walter Mignolo, profesor, en las aulas de la UASB, en Quito" (Mignolo y Gómez, 2012: 11). El evento, teórico y expositivo, tuvo lugar en 2010 siguiendo los pasos de dos exposiciones celebradas un año antes: Altermoderno (Tate Britain) y Modernologías (Museo de Arte Contemporáneo de Barcelona). Así, de las aulas de la UASB a espacios expositivos de Londres, Barcelona y Bogotá, se perfilan los lugares de debate entre el altermundialista francés Nicolas Bourriaud, autor del Manifiesto Altermoderno, y el decolonial argentino 
Walter Mignolo promotor del Decolonial Aesthetics. Para éste último la crítica a la estética "equivale a contribuir a la descolonización del ser, el saber y el sentir. [...] El arte no sólo revela la herida colonial sino que puede, en determinadas circunstancias, contribuir a su sanación" (Carballo y Mignolo, 2014: 18). Reconoce Mignolo que el colombiano Albán-Achinte introdujo la cuestión estética en el proyecto decolonial en 2005, pero que para él devino importante en 2009 cuando siete alumnos del doctorado de estudios culturales de la UASB presentaron sus investigaciones. Entre ellos, el colombiano Pedro Pablo Gómez director de la revista de arte Calle 14 que desde 2010 difunde la estética decolonial, y la ecuatoriana Mayra Estévez, futura subsecretaria de artes y creatividad del Ministerio de Cultura de Ecuador. Es en esos circuitos a los que no acceden la mayoría de los subalternizados, ni de los damnés de la terre (Fanon, 1961), ni de los shuar de la amazonía a pesar de poseer teléfonos móviles (de Salvador y Martínez, 2015), donde se producen neologismos que se propagan sin que reflexionemos sobre los mecanismos sociales a través de los que circulan internacionalmente, y sin que prestemos atención a que "la eficacia simbólica de los temas de la nueva vulgata mundial se debe en gran parte a que son dirigidos por especialistas de unas disciplinas que se perciben como marginales $y$ subversivas, como los cultural studies [...] de forma que a ojos de los escritores de las antiguas colonias europeas adquieren trazas de mensajes de liberación" (Bourdieu y Wacquant, 2001: 48). Ante ellos, y también ante jóvenes artistas e investigadores/as científico-sociales que, parafraseando a los decoloniales, viven en el norte global. Porque las dimensiones de ese hecho social están interconectadas y son globales, hay que pensar los efectos que en cada contexto local tiene la difusión -de congreso en congreso, de museo de arte en centro de cultura contemporánea, de universidad en universidad- de neologismos que al "condensar y poner en circulación toda una filosofía del individuo y de la organización social, están capacitados para funcionar como auténticas consignas políticas" (id: 14). Esos neologismos, entre los que figura el de decolonial, "enredan el lenguaje, dejando paralogizados a sus objetos de estudio -los pueblos indígenas y afrodescendientes- con quienes creen dialogar [...] (y) crean un nuevo canon académico, utilizando un mundo de referencias y contrarreferencias que establece jerarquías y adopta nuevos gurús: Mignolo, Dussel, Walsh, Sanjinés" (Rivera Cusicanqui, 2010: 64). Para esta historiadora boliviana aymara-europea, el capital cultural y simbólico de esos nuevos gurús proviene de su reconocimiento por la Academia estadounidense.

Reteniendo estas problemáticas veremos cómo un gobierno populista (Laclau, 2005) como el ecuatoriano de la revolución ciudadana, utiliza la decolonialidad, la interculturalidad y el Sumak Kawsay (Buen Vivir) (Bretón; Cortez; García, 2014), como consignas políticas escenificándolas gracias a mass-mediáticas teatralizaciones a través de las que construye lo que Sousa Santos (2008) denomina "posmodernidad celebratoria”. Ese uso permite a dicho gobierno presentar los procesos neoliberales en curso como resultado de un proyecto social, económica y culturalmente emancipador que recoge e intenta materializar las 
principales demandas de diferentes movimientos y/o colectivos sociales. En países como Ecuador, al igual que en otros de la Abya Yala, esa mistificación se produce en una etapa caracterizada como post-neoliberal (Martínez Novo, 2014) en la que actúan gobiernos deseosos de "re-fundar" el Estado y de hacer frente al Capital y al Mercado. Analizar esa mistificación requiere tener presente que nociones como las de interculturalidad, decolonialidad y Sumak Kawsay, además de estructurar discursos emancipadores, deben concretarse políticamente. Y también hace necesario estar alerta para que "las ciencias sociales y la filosofía críticas no se conviertan en "tontos útiles" de una globalización con etiqueta de intercultural" (Estermann, 2014: 5). Como parte fundamental del quehacer antropológico se basa en la práctica etnográfica, utilizaré datos obtenidos en Quito, Guayaquil y Loja ${ }^{1}$ para mostrar cómo las citadas nociones estructuran los planes de política cultural de un Estado ecuatoriano cuya Constitución de 2008 declara intercultural y plurinacional, y que entroniza el Sumak Kawsay haciendo de él el principio orientador de todas las políticas de Estado (cultura, salud, educación). Esas nociones también forman parte del léxico de quienes desean decolonizar la universidad (Castro-Gómez, 2007) y construir conocimientos in-disciplinados (Wlash y Schiwy; Castro-Gómez, 2002) liberados de la modernidad occidental y de sus saberes ideológica, racial, religiosa y sexualmente sesgados. Y también del de líderes históricos del movimiento indígena (Macas, 2005) y del de los miembros de un gobierno que en 2007 creó el Ministerio de Cultura y que quiere establecer cuatro universidades emblemáticas, entre ellas la de las Artes (UARTES) ${ }^{2}$. Esa universidad se proyecta hacia el futuro como un centro que formará profesionales capaces de desarrollar nuevas industrias creativas ${ }^{3}$, y artistas que puedan inscribirse en el campo internacional del arte contemporáneo. Como el proyecto no parece orientado por ningún tipo de decolonialidad epistemológica, económica, política o estética, sorprende que el neologismo figure entre los principios de la UARTES. $\mathrm{Su}$ presencia puede interpretarse como producto de una reflexividad institucional (Méndez, 2005) entre los parámetros establecidos por los estudios culturales de la UASB, y significativos agentes del campo político, académico y cultural ecuatoriano. Agentes que, 1. Como miembro del Proyecto I+D+i (2012-2014) "Impactos del reconocimiento de la interculturalidad y la plurinacionalidad en los sistemas educativo, cultural y de salud de Ecuador" dirigido por el Dr. Isidoro Moreno. Universidad de Sevilla.

2. Las otras son: UNAE (Pedagogía), IKIAM (Ciencias de la Tierra y de la vida), YACHAY (ciudad del conocimiento). Cada una depende de un Ministerio u organismo diferente. La UARTES del Ministerio de Cultura, la UNAE del de Educación, la IKIAM del Coordinador del Conocimiento y del Talento Humano, y la YACHAY del SENESCYT.

3. La noción de industrias creativas es más amplia que la de industrias culturales propuesta por Adorno y Horkheimer pero ambas forman parte de la economía de la cultura. El incremento de industrias creativas es parte de una estrategia política destinada a ampliar mercados y fomentar la inclusión social y el desarrollo sostenible. Dichas industrias incluyen formas de expresión artística y/o cultural, artesanía, diseño, patrimonio cultural, turismo cultural, etc. 
aún habitando la herida colonial (Anzáldua, 1987), tienen mayoritariamente en común no ser indígenas, ser varones, de clase media, y con estudios universitarios realizados dentro y fuera del país. Mientras que el uso retórico que dichos agentes hacen de la decolonialidad y la interculturalidad contribuye a ocultar un creciente neocolonialismo académico (Villavicencio, 2013), la narrativa de la decolonialidad al desatender las dinámicas internas de los grupos subalternizados (Rivera Cusicanqui, 2010) impide articular un proyecto político emancipador. Antes de abordar estas cuestiones recordaré algunas claves del proyecto Modernidad/Colonialidad/De-colonialidad (MCD) ${ }^{4}$, y una premonitoria preocupación sobre el quehacer antropológico formulada por Clifford Geertz.

\section{DECOLONIALIDAD, QUEHACER ANTROPOLÓGICO Y ESTÉTICA DECOLONIAL}

No abordaré los agrios disensos, tan habituales en la Academia pero que sorprende encontrar entre in-disciplinados y decoloniales, que enfrentan entre sí a algunos de los principales artífices de la opción decolonial (Castro-Gómez, 2012; Grosfoguel, 2013). Una opción fundamentalmente desarrollada por varones originarios de diferentes países de América Latina, académicamente formados dentro y fuera de sus países, procedentes de diversas disciplinas, y para quienes "la misión del intelectual descolonial pasa por pluralizar el campo del conocimiento y la sensibilidad; de las prácticas y de las creencias."(Carballo y Mignolo, 2014: 16). Tampoco ahondaré en el olvido de las categorías de género y sexualidad, ni en cómo tras la crítica de las feministas decoloniales éstos las incorporarán como una retahíla a sus discursos. Retahíla que les sirve para afirmar que la modernidad, y al parecer sólo ella, "produce heridas coloniales, patriarcales (normas y jerarquías que regulen el género y la sexualidad, y racistas (normas y jerarquías que regulen la etnicidad" (id: 11), y que la colonialidad o matriz colonial de poder tiene que ver con estrategias imperiales de control que abarcan desde los recursos naturales hasta el conocimiento, pasando por cuerpos, géneros y sexualidades. En este epígrafe quiero, primero, recordar la dialéctica colonialidad/decolonialidad para ver si la retórica decolonial se ha convertido en tonta útil al servicio de una globalización post-neoliberal que fagocita lo político mediante una estetización celebratoria de todo tipo de diversidades (étnico/ raciales, sexo/genéricas, sexuales u otras). Y, segundo, rememorar una reflexión sobre los caminos a seguir por una antropología, hija del imperialismo occidental (Gough, 1968), que dio "forma a un sistema/mundo localizado en los EEUU, Gran Bretaña y Francia, que define la política, que domina la producción, difusión y el consumo de conocimientos

4. El proyecto en el que entre otros participaron Quijano, Escobar, Dussel, Mignolo, Walsh, Lander, Castro-Gómez y Grosfoguel, se desarrolló a partir de 1998 arraigándose en el doctorado de estudios culturales de la UASB dirigido por Walsh. 
sobre otros pueblos y culturas" (Lins-Ribeiro, 2011: 71). Una localización territorial y lingüística que quienes postulan la opción decolonial dicen no abandonar porque " $e l$ control epistémico (colonialidad del ser y del saber) se ejerce en inglés, francés y alemán [...] Tú puedes decir, ah bueno, para ser reconocido. Sí, para ser reconocido en la disidencia [...] Pensar descolonialmente significa, pues, actuar y despensar en inglés" (Carballo y Mignolo, 2014: 29). Es así como, revestida de disidencia, los decoloniales perpetúan la localización producto del sistema/mundo colonial. Y así como, probablemente, se justifique que Decolonial Aesthetics sólo exista en inglés, y que la Decolonial Summer School se desarrolle en Middelburg siendo el tema de 2014 Democratic and Decolonial Futures con énfasis en el sumak kawsay and the birth of plurinational states in Latin America5. Un nacimiento lejos de materializarse en Ecuador o Bolivia, dos países cuyas Constituciones recogen la plurinacionalidad y el Sumak Kawsay.

Voy pues a por el primer objetivo. Cuenta la historia narrada desde el proyecto MCD que a principios de los noventa del siglo XX el sociólogo peruano Aníbal Quijano acuñó la noción de colonialidad. Esa noción superadora de la de colonialismo remite a la compleja estructura de control y gestión del patrón colonial del poder. Así mismo insistirá el sociólogo en que la colonialidad, entendida como la lógica cultural del colonialismo, persiste reproduciéndose sociológicamente en los estados-nación post-coloniales. Para él es la "instrumentalización de la razón por el poder colonial, en primer lugar, la que produjo paradigmas distorsionados de conocimiento y malogró las promesas liberadoras de la modernidad. La alternativa en consecuencia, es clara: la destrucción de la colonialidad del poder mundial" (Quijano, 1992: 437). Incido en esta visión porque la colonialidad es central en un MCD desde el que se piensa la herencia colonial de las Américas atendiendo a tres ejes estructurales: el del poder, el del saber y el del ser. Y también para señalar que, desde otras perspectivas, se sostiene que el pensamiento descolonizador ya lo habían producido poblaciones e intelectuales indígenas de Bolivia, Perú y Ecuador (Rivera Cusicanqui, 2010). Explica esta autora que cuando una revista inglesa le sugirió sustituir la noción de colonialismo interno acuñada en 1969 por Pablo González Casanovas y que ella utilizaba, por la de colonialidad del saber de Quijano, cayó en cuenta de cómo se formaba "el canon de una nueva área del discurso científico-social, que visibiliza ciertos temas y fuentes, pero deja en la sombra a otros" (Rivera Cusicanqui, 2010: 68). Por eso en vez de la geopolítica del conocimiento preconizada desde el MCD, propone desarrollar una economía política del conocimiento susceptible de desvelar lo que económica y materialmente actúa tras los discursos. Propuesta que no parece interesar a un MCD desde el que lo fundamental sería decolonizar la epistemología "para dar paso a una nueva comunicación intercultural, a un intercambio de experiencias y de significaciones, como la base de otra racionalidad que pueda pretender, con legitimidad, a alguna universalidad"

5. Ver: https://transnationaldecolonialinstitute.wordpress.com 
(Quijano, 1992: 447). Complejo objetivo arraigado en los estudios culturales y que afecta a la antropología producida en América Latina obteniendo tan desiguales resultados (Quintero y Petz, 2009; Ramos, 2011; Garbe, 2012) que cabe preguntarse si eso tendrá que ver con el hecho de que, desde la antropología, se aborda lo empírico mediante lo que sigue siendo su método y técnica distintiva: una observación directa enmarcada en trabajos de campo de una temporalidad relativamente larga.

Esa pregunta me ha hecho recordar a un Geertz que se interrogaba sobre cómo desempeñar en el siglo XXI el oficio de antropólogo. Para responder confrontó los resultados del quehacer investigador de Clastres, con su trabajo de campo de un año, y los de Clifford "historiador de las ideas, autorreciclado primero a la antropología y luego a los estudios culturales" (Geertz, 1999: 137), basado en itinerarios por museos y exposiciones. Según Geertz este último quería establecer nuevas bases para una disciplina que debía enfrentarse a una interconexión mundial que facilitaba hibridaciones, y a un mundo en el que coexistían múltiples políticas anti hegemónicas. Consciente de esa nueva realidad, se preguntaba Geertz cómo mantener la tradición de investigación sobre la que se había elaborado "una disciplina blanda y tal vez a medio formar, pero moralmente fundamental; y desplazar, reelaborar, renegociar, re-imaginar esa tradición para favorecer un enfoque pluralista, dialógico, múltiplemente centrado" (id: 149). Para él, las obras de quienes como Clifford defendían una drástica reducción o transformación del trabajo de campo y practicaban una especie de "investigación-carrera”, ni suponían avance alguno para la antropología, ni parecían representar una tendencia de futuro. Compartiendo lo primero, me temo que quienes desarrollamos un quehacer antropológico en países del sur del norte global, que dirían los decoloniales, practicamos cada vez más una "investigacióncarrera" centrando nuestra práctica etnográfica en actividades (entrevistar, fotografiar, observar, filmar, etc.,) realizadas durante lo que seguimos llamando -por inercia o falta de reflexión crítica- trabajo de campo. No se trata de resucitar a Clastres pero sí de plantear si es posible -y cómo lo es- elaborar conocimiento antropológico a partir de prácticas etnográficas que no suelen asentarse sobre trabajos de campo que permitan una interacción prolongada con, en este caso, quienes habitan la herida colonial. Aproximarse a esos sujetos heterogéneos que en sus contextos locales ocupan desiguales y jerárquicas posiciones de poder/saber, producto de una dialéctica colonialismo-colonialidad que articula sexo, género, clase, raza/etnicidad y prácticas sexuales, exige realizar un trabajo de campo lo más alejado posible del de la "investigación-carrera”. Recuperar esa temporalidad permitiría ahondar los retos que conlleva decolonizar el saber, el poder, el ser y, estética decolonial obliga, también el ver. Si se pretende seguir elaborando conocimiento desde la antropología no se necesita indisciplina -esa ya abunda-, sino revisar sus métodos y volver a realizar trabajos de campo más próximos a la práctica etnográfica de Clastres que a la “investigación-carrera” de Clifford. 
Sin embargo la revisión disciplinar es algo a lo que no aspira el "pensar y hacer decolonial porque no es un método, sino una vía, un camino para rehacernos en la búsqueda de formas de vivir y de gobernar(nos) en la que no vivamos para trabajar/producir/consumir, sino que trabajemos para con-vivir" (Mignolo, 2014: 11). Y elaborar conocimiento es algo que la decolonialidad rechaza porque, declarándose opción, postulan que eso también convierte en opciones a las disciplinas, los sistemas de ideas, o las creencias. Esa forma de entender la decolonialidad, que no todos quienes participan en el MCD comparten, la convierte en una especie de filosofía new age que se plasma en el campo del arte gracias a proyectos iniciados a finales de 2012, como Decolonizando el Conocimiento y las Estéticas (Matadero Madrid, 2013), que son resultado de una colaboración institucional entre ese Centro de Creación Contemporánea y el de Estudios Postcoloniales de Goldsmith. En cada contexto local, proyectos de ese tipo contribuyen a una progresiva estetización de lo político y a fomentar una posmodernidad de celebración que dificulta la emergencia de una oposición (Sousa Santos, 2008). Ese modo de comprender la decolonialidad también deja intactos los mecanismos de exclusión y legitimación que condicionan las trayectorias de quienes actúan en el campo del arte: sexo/género, raza/etnicidad, clase social. Pero dado el actual contexto político, académico y artístico la decolonialidad seduce, al presentarse y difundirse transnacionalmente como una opción de vida revestida con un aura de radicalidad política, personal y estética. Eso quizás explique por qué en 2012 Inti Muenala, artista visual kichwa afincado en Chicago y que expuso en la $I V$ Bienal de Arte Indígena Ancestral y Milenario 6 , organizó en su ciudad de origen, Otavalo, "un encuentro para descolonizar la estética, era todo como un formato de conversatorio, de reflexión, por parte de un colectivo de artistas indígenas. [...] Y parece que hubo muchas posiciones diferentes. Unas más esencialistas y más folclóricas, otras más de conversar y reflexionar críticamente sobre el devenir del arte indígena. Lo que tenemos como mucho acá en el Ecuador, y que habrás visto en la Bienal, es a artistas que se identifican, que están participando en la construcción de una visualidad indígena muy compleja, relacionada más con el folclor, con esencialismo". Esta informante entrevistada en noviembre de 2012, historiadora del arte, profesora universitaria y curadora, relacionaba esa situación con un Ministerio de Cultura "que tiene inconsistencias bestiales, como todo el gobierno de Correa..., claro es que se ocupa de interculturalidad, y ese es un tema super difícil porque es lograr un diálogo equitativo entre diferentes cosmovisiones, conocimientos, lenguajes, es como un paso hacia la decolonización... pero está por construirse, al menos en el campo de la cultura". Fue el silencio de esta informante -y el de otras y otros- ante mi pregunta sobre qué impedía construir la interculturalidad en un campo como el de la cultura y el arte, el que me llevó hasta los planes de política cultural del Ministerio de Cultura de Ecuador.

6. La Bienal se lleva a cabo desde 2006 y hasta 2012 la apoyaron diferentes instituciones y organizaciones indígenas. 


\section{UN MINISTERIO DE CULTURA, SIETE MINISTROS Y DOS PLANES DE POLÍTICA CULTURAL}

Desde 2007 los sucesivos gobiernos de Ecuador, todos ellos presididos por el economista Rafael Correa, dicen estar haciendo realidad una revolución ciudadana ${ }^{7}$ tendente al Sumak Kawsay, siendo la creación del Ministerio de Cultura (MC) la prueba de que el desarrollo cultural es una política de Estado, y que el Sumak Kawsay ${ }^{8}$ no puede construirse sin el arte y la cultura. Desde su puesta en marcha en 2007 el MC, que ya ha sido dirigido por siete personas, diseña la política cultural del país. Desde el poeta esmeraldeño Antonio Preciado nombrado por un recién elegido Rafael Correa deseoso de "demostrar las potencialidades del pueblo afroecuatoriano", hasta un Paco Velasco que ignorará la propuesta de su antecesora Erika Sylva (2010-2013), una constante del MC ha sido no aplicar dos planes de política cultural sustancialmente diferentes: el firmado en octubre de 2007 por Preciado, y el suscrito por Sylva en julio de 2011. Tan diferentes como el contexto político y económico en el que se gestaron. Recuerda esta pintora y galerista entrevistada en Quito en octubre de 2012 que, en un país asolado por la crisis financiera de 1999 que obligó a cerrar galerías y dinamitó el escaso mercado del arte, "se creaba un Ministerio nuevo y era muy ilusionante. El primer ministro negro que hubo en el país fue para cultura. Se llamaba Antonio Preciado, demasiado bueno... ahí empezó lo malo. Él venía arrastrando toda la cuestión del racismo, y todo esto era nuevo. En el Ministerio se creó un departamento que iba a tratar los temas de interculturalidad, de toda la cultura de los pueblos, [...] porque somos 32 nacionalidades en Ecuador, y cuando veía yo, que me incorporé en 2008, que una persona que había escrito en su vida un poema estaba de director de interculturalidad me quedaba con la mandíbula caída. Y Antonio ya no pudo más. Le pusieron a un viceministro que era un hombre de ojo azul que estudió en Francia, y no tenía idea de lo que es cultura. [...] Entonces empezó una divergencia tan terrible, y el Ministro era tan buena gente, que le fue dando espacio a lo que decía el que había pasado por la Sorbona. Y al poco renuncia el Ministro, o le botan, no sé”.

Renunciara al cargo o le echaran de él, buen indicador de la posición política que en 2007 ocupaban en Ecuador algunas organizaciones indígenas y de mujeres es que, para

7. Que engloba otras seis: la constitucional y democrática, la ética, la económica-productiva y agraria, la social, la de la dignidad. La revolución cultural se incorporó al Programa de Gobierno 2013-2017.

8. Así lo dijo en su discurso la Ministra de Cultura durante la toma de posesión de las nuevas autoridades de la Casa de la Cultura. Quito. 30.08.2012.

9. El Universo. 13.12.2006. 
elaborar el Plan Nacional de Cultura del Ecuador ${ }^{10}$, Preciado convocó durante dos meses un "Diálogo para el Plan Nacional de Cultura" y recabó "propuestas, demandas y criterios a representantes del Consejo de Desarrollo de las Nacionalidades y Pueblos del Ecuador (CODENPE), del Consejo del Pueblo Afro-ecuatoriano del Ecuador (CODAE), del Consejo Nacional de la Mujer (CONAMU), de la Mesa de Diálogo de Cultura convocada por la Secretaría Nacional de Planificación y Desarrollo (SENPLADES), y de la Casa de la Cultura Ecuatoriana". Para este Ministro, las aportaciones de esos colectivos le habían permitido "identificar algunos aspectos o temas de absoluta coincidencia, e incluso de consenso [...] 1. El Plan y las politicas culturales del país deben identificarse y desarrollarse a partir del enfoque de Derechos Culturales para los ecuatorianos [...] 3. Se torna impostergable asumir la interculturalidad [...] como un enfoque esencial de las políticas públicas. [...] 5. Asumir la diversidad cultural del país no desde una perspectiva únicamente etnicista [...] 6. Incorporar el concepto de Equidad como eje estratégico de la política cultural pública [...] 7. Proponer la participación [...] como un proceso consustancial a la construcción de políticas culturales". Ni el Sumak Kawsay ni la decolonialidad forman parte del léxico de este Plan que podríamos calificar como "moderno" y que recoge líneas de política cultural ya propuestas (Moreira, 1977). Pero el problema de fondo y que parece persistir es otro. Rememorando esos mismos años, el poeta ecuatoriano que entrevisté pocos días después de la citada pintora hizo emerger otros protagonistas al insistir en la inestabilidad política por la que atravesaba un país en el que los movimientos populares e indígenas habían "derrocado a varios presidentes. Entonces surge este candidato, Correa, más bien desconocido pero vinculado con ciertos sectores de izquierda, y dentro de ellos aparece también Pachakutik-CONAIE ${ }^{11}$. Y de ahí surge la idea, de alguno de esos intelectuales izquierdista, la idea del Ministerio de Cultura. Pero cuando llegan al gobierno en realidad no tienen ni idea de para qué lo quieren. Yo diría que fue un cálculo personal de Galo Mora, claramente fue él, pero cuando triunfa Correa [...] al poco se lo lleva como secretario de Presidencia. Y entonces no saben qué hacer con ese Ministerio. Tanto que entonces nombran a un poeta, Antonio Preciado, muy buena persona. Cuando lo nombraron, es que mira, todos los que le conocíamos sabíamos que no iba a pasar absolutamente nada. [...] Y ahora tenemos a la Erika Sylva que introduce esta línea mucho más folclorizante. No tiene la menor comprensión ni antropológica, ni tradicional, ni..., y se aferra a las categorías UNESCO... Entonces dicen que el Ministerio de Cultura es intercultural, ¿cómo se expresa

10. Plan Nacional de Cultura del Ecuador: Un camino hacia la revolución ciudadana desde la cultura. 2007-2017. Un documento para la participación, el diálogo intercultural y la reconfirmación identitaria. Quito. Octubre de 2007. Mientras no indique lo contrario los entrecomillados remiten a este documento.

11. Pachakutik es un movimiento de unidad plurinacional surgido en 1995 para representar los intereses del movimiento indígena liderado por la CONAIE (Confederación de Nacionalidades Indígenas del Ecuador) fundada en 1986. 
eso? [...] yo he sido entrevistado en dos ocasiones por gente de ese Ministerio y no acabo de ver ni una política consistente de coherencia gubernamental, ni de Estado. Más bien lo que diría es que se da un proceso de folclorización de las culturas indígenas, de las culturas populares".

Ese proceso se vislumbra en Políticas para una revolución cultural ${ }^{12}$ firmado en 2011 por una Erika Sylva que elegirá el slogan Somos Cultura como seña de identidad del MC. Contrariamente al de Preciado, éste Plan se elaboró gracias a dos asesores y se nutrió de "comentarios y aportes del equipo técnico del Ministerio de Cultura", reconociendo la Ministra la necesidad de "propiciar una mayor socialización y validación de sus contenidos". Esta primera gran diferencia entre la gestación de ambos planes responde a un doble fenómeno que en 2007 o bien no existía o era incipiente: el de la cooptación de personas que podían ser socialmente percibidas como representantes de diferentes diversidades: indígenas, mujeres, afro-descendientes, discapacitados..., y el de la pérdida de terreno político de las organizaciones indígenas. La segunda gran diferencia son tres de sus cuatro ejes: "descolonización, derechos culturales, emprendimientos culturales, nueva identidad ecuatoriana contemporánea, mediados por otros cuatro transversales: interculturalidad, equidad en sentido integral (de género, étnica, intergeneracional), fortalecimiento de la institucionalidad ligada al quehacer cultural, y posicionamiento internacional de la cultura ecuatoriana diversa". Redactado con largas notas a pie de página y referencias a Mignolo, Quijano, Walsh, Lander o Grosfoguel, este Plan también propone sustituir la idea de Ecuador como una "pequeña gran nación de cultura" formulada por Benjamín Carrión fundador en 1944 de la Casa de la Cultura ecuatoriana, por la de "potencia megadiversa", que incorpora una dimensión económica "al comprobarse esta ancestral cualidad natural y cultural que vincularía a las culturas y pueblos ancestrales, con los pueblos y las culturas presentes, proporcionándoles un modelo alternativo de vida (utopía) basado en el Sumak Kawsay". Obsérvese que es a las culturas subalternizadas a las que el Plan pretende proporcionar ese modelo alternativo de vida reproduciendo "una inclusión condicionada, una ciudadanía recortada y de segunda clase que modela imaginarios e identidades subalternizadas al papel de ornamentos o masas anónimas que teatralizan su propia identidad" (Riversa Cusicanqui, 210: 60). Reflejo de los intereses de una parte de las nuevas élites ecuatorianas presentes en la academia, la cultura y, claro está, el gobierno, el Plan postula descolonizar la matriz cultural heredada del pasado colonial y apuesta por una economía del conocimiento y de la cultura basada en impulsar las industrias creativas. Para la Ministra esa economía sólo es posible articulando el Sistema Nacional de Cultura y el de Ciencia, Tecnología, Innovación y Saberes Ancestrales. He afirmado que sólo parte de las nuevas élites ecuatorianas sustentaron ese Plan porque cuando

12. Políticas para una Revolución Cultural. Ministerio de Cultura. Quito 2011. Hasta que no indique lo contrario los entrecomillados remiten a este documento. 
la Ministra propuso que el Sistema Nacional de Cultura se adscribiera al Ministerio Coordinador del Conocimiento y del Talento Humano, y no al de Desarrollo Social, fue sustituida por Paco Velasco. Éste dirigió durante poco más de un año un MC renombrado en 2013 Ministerio de Cultura y Patrimonio.

Reunir en un mismo Ministerio Cultura y Patrimonio indica la persistencia de un imaginario hegemónico sobre las culturas indígenas, y la voluntad de desarrollar una economía capitalista en torno a productos concebidos como culturalmente distintivos. La creciente atención prestada -vía patrimonialización de la cultura material e inmateriala aquellas prácticas y productos de los pueblos y nacionalidades de Ecuador lleva, como me explicaba a finales de 2012 un responsable de la Confederación de Pueblos de la Nacionalidad Kichwa del Ecuador (ECUARUNARI), a su folclorización: "señores indígenas vengan por favor con sus trajes propios e inviten a pasar a los señores embajadores [...] van a poner a nuestros compañeros [...] como elementos vivos folclóricos, adornos vivos ahí en los salones en los que se reúnen a hablar [...] ¿por qué no nos invitan a discutir políticas culturales?". No se les invita porque, interpretaba un informante mestizo profesor de arte en una Universidad privada, "seguimos con un tufo racista: los indígenas son ellos, los no indigenas nosotros, nosotros hacemos un arte internacional, los indígenas están ligados a lo etnográfico, a lo ancestral. Nada de eso está resuelto. [...] Tras 2008 se usa lo folclórico, lo ancestral, con fines de aplacamiento. [...] Y eso le viene bien a un Ministerio de Cultura que sólo tiene una línea clara de actuación, la de instrumentalizar el tema cultural indígena". Un Ministerio bajo cuya responsabilidad estará la emblemática UARTES y cuya dirección asumirá Paco Velasco, sin retener las políticas de la revolución cultural ${ }^{13}$ diseñadas por su antecesora.

\section{RENOVACIÓN UNIVERSITARIA A RITMO DE REVOLUCIÓN CIUDADANA}

"En el proyecto de las universidades emblemáticas es donde más se nota la desarticulación con los actores, porque nace del gobierno, no nace de los actores, no nace de nuestra voluntad". Así me hablaba en 2012 un profesor de la UASB para quien algo similar sucedía con la política cultural. "Pensar la diversidad desde los grupos sociales, políticos, desde el movimiento indígena, desde el movimiento afro..., ese es un proceso super-avanzado que me parece que no está siendo recuperado por las políticas culturales del gobierno. Si es que tú indagas en esas políticas culturales oficiales, no encuentras esos procesos que vienen de abajo, ese es el problema... La Universidad también ha pensado mucho la interculturalidad, la diversidad, y ahí también podrías cuestionar, a ver dónde está ese diálogo con las bases, con esos pueblos... y tampoco lo vas a encontrar". Esta reflexión nos sitúa de lleno ante el proyecto, el de crear cuatro grandes universidades emblemáticas, que mejor plasma

13. Ver la propuesta 21 del Programa de Gobierno 2013-2017. 
cómo el Presidente Correa y René Ramírez, presidente del CES y del SENESCYT ${ }^{14}$ y uno de los ideólogos del gobierno de la revolución ciudadana, hacen un uso retóricoestratégico de la decolonialidad, el Sumak Kawsay ${ }^{15}$ y la interculturalidad. Un proyecto que "es un plan Bolonia a ritmo de revolución ciudadana....imaginate lo que puede salir de ahí $i$ ", me decía otro informante. Un ritmo muy rápido que exigió volver a evaluar ${ }^{16}$ las veintiséis universidades (públicas y privadas) que un informe de 2009 había considerado que incumplían los parámetros de calidad requeridos. Catorce fueron eliminadas en 2012 por seguir estando en la peor categoría posible: la $\mathrm{E}$.

El 4 de noviembre de 2013, tras un año de prorroga, también se cerró la Universidad Intercultural de las Nacionalidades y los Pueblos Indígenas Amawtay Wasi ${ }^{17}$ creada por la Confederación Nacional Indígena de Ecuador (CONAIE) y a la que aludía en 2004 un Aníbal Quijano que la consideraba una materialización de los logros del movimiento indígena. Materialización que se concretaba justo cuando se estaba produciendo "una profunda revolución en el terreno del conocimiento y del pensamiento a nivel mundial, y América Latina es uno de sus centros"18. Un año antes de esas declaraciones y tras afirmar la necesidad de pensar los problemas sociales para intervenir en ellos, una de las figuras de los estudios culturales de la UASB sostenía que, en Ecuador, la crisis subyacente al estudio del otro y de la cultura desde la antropología se relacionaba con "la clara iniciativa histórica del movimiento indígena como actor y sujeto social y político. [...] Además, a partir de sus propias iniciativas académicas, incluyendo dentro

14. Consejo de Educación Superior (CES). Secretaría Nacional de Educación Superior, Ciencia, Tecnología e Innovación (SENESCYT).

15. Plan Nacional para el Buen Vivir 2009-2013. René Ramírez lo define como "la satisfacción de las necesidades, la consecución de una calidad de vida y muerte dignas, el amar y ser amado, y el florecimiento saludable de todos y todas, en paz y armonía con la naturaleza y la prolongación indefinida de las culturas humanas. El Buen Vivir supone tener tiempo libre para la contemplación y la emancipación, y que las libertades, oportunidades, capacidades y potencialidades reales de los individuos se amplíen y florezcan de modo que permitan lograr simultáneamente aquello que la sociedad, los territorios, las diversas identidades colectivas y cada uno -visto como un ser humano universal y particular a la vez-valora como objetivo de vida deseable (tanto material como subjetivamente, $y$ sin producir ningún tipo de dominación a un otro)".

16. Evaluación efectuada por el Consejo de Evaluación, Acreditación y Aseguramiento de la Calidad de la Educación Superior (CEAACES).

17. Según El Comercio.com obtuvieron 26,9 sobre 100 y la evaluación fue específica. Según el CEAACES participaron "profesionales de diversas ramas de las ciencias sociales, incluso de las nacionalidades kichwa y shuar, que pidieron aplicar criterios de interculturalidad. [...] Hubo 50 indicadores, 11 particularmente diseñados para una institución intercultural de educación superior".

18. Universidad de Santiago de Compostela, 2004. http://firgoa.usc.es 
de ellas la recientemente formada Universidad Intercultural de las Nacionalidades y Pueblos Indígenas, también ponen en cuestión y crisis la futura función y validez de los departamentos de antropología" (Walsh, 2003: 20). Al parecer ni el movimiento indígena ni la Amawtay Wasi cuestionaban unos estudios culturales, novedoso crisol de opciones inter-trans-in-disciplinares, que se abrían camino en un sistema universitario en el que, según un académico entrevistado, la antropología estaba poco presente. Excepto "en la FLACSO y en la Católica, que fundó una Facultad juntando antropología, filosofía, historia..., pero luego en un momento reaccionario el siguiente Rector mandó Filosofía a Teología.., y la antropología fue decayendo, y eso pasó. Hoy no hay lugares para estudiar antropología, salvo en la FLACSO que es una institución de formación de tecnócratas, y no académica en el sentido de reflexionar, de pensar". Dudo que la crisis del estudio del otro y de la cultura desde la antropología respondiera en exclusiva a la emergencia del movimiento indígena como sujeto social y político, y también que la recién creada universidad intercultural cuestionara la validez de los departamentos de antropología. A mi entender la interpretación de Walsh responde más a la voluntad de presentar los estudios culturales como una alternativa libre de la colonialidad del saber, que a la iniciativa de la CONAIE de fundar la Amawtay Wasi añadiendo así un centro más a la red iniciada en 1986 con la fundación del Instituto Científico de las Culturas Indígenas. Instituto al que no aluden desde la opción decolonial ni siquiera quienes afirman que ésta es una herramienta de análisis y eje de lucha de dos países, Ecuador y Bolivia, "envueltos en la labor de re-fundar el Estado e interculturalizar, plurinacionalizar y descolonizar sus estructuras e instituciones" (Walsh, 2008: 135). Dos países en los que, insiste esta autora, urge acabar con la colonialidad del saber que impone una única racionalidad epistémica eurocéntrica "particularmente evidente en el sistema educativo, desde la escuela hasta la universidad" (id: 137). Cinco años después y utilizada como consigna política, la denuncia de la colonialidad del saber está sirviendo para legitimar la post-neoliberal reestructuración de un sistema universitario que, "en ausencia de sólidos puntos de anclaje alrededor de los cuales articular los cambios necesarios, está conduciendo a trasplantar, sin criterios de pertinencia, modelos y esquemas [...] que nos están conduciendo a una suerte de neocolonialismo académico" (Villavicencio, 2013: sp).

Esa reestructuración ya no afectará a la Amawtay Wasi, cerrada por "la actitud racista de un gobierno que lo único que ha hecho es eliminar todos nuestros espacios ganados a lo largo del tiempo y que en vez de progresar en la conquista de nuestros derechos ha fomentado un efecto regresivo. Tal como dice Catherine Walsh, entonces ¿debemos pensar ahora si las experiencias de educación alternativa deben seguir llamándose Universidad?" ${ }^{19}$. Más allá de la indudable pertinencia de la pregunta planteada, y de la necesaria denuncia de la

19. Extracto de la carta de agradecimiento del Rector por los apoyos recibidos tras el cierre (5.11.2013) www.amawtaywasi.edu.ec. Actualmente la institución se autodesigna Universidad Comunitaria Intercultural Amawtay Wasi. 
progresiva eliminación de espacios de gran relevancia simbólica obtenidos gracias a las luchas del movimiento indígena (Muyolema, 2015), hubiera sido interesante volver a enunciar, pero el Rector no lo hace en su carta y la pedagoga Walsh tampoco, qué tipo de educación alternativa recibieron los trescientos estudiantes que se formaron en ella enmarcados por un sistema diferente en el que no existían facultades y escuelas, carente de infraestructura propia y funcionando en espacios prestados por las comunidades. Lo que en su carta enfatizará el Rector será la cuestión de la lengua vehicular, el kichwa, y la de la interculturalidad. Dos cuestiones de gran relevancia para el proyecto cultural del movimiento indígena (Martínez Novo, 2009) y que también retiene ese Proyecto de la revolución cultural que es la UARTES ${ }^{20}$, inscrito en el "espacio geopolítico epistémico del Sur" y destinado a promover "la deconstrucción del arquetipo ideológico heredado de los procesos coloniales". La UARTES, afirman los mandatarios ecuatorianos, surge porque no existe "un sistema integral de educación y formación artística, producto del abandono histórico del Estado en el campo de las artes y las culturas, lo que ha propiciado una oferta académica en artes caracterizada por la inequidad social, étnica y de género; la masificación de las universidades públicas; su baja calidad; la ausencia de orientación hacia la producción de conocimientos; y una desarticulación de las necesidades de desarrollo del país”. Para corregir esa situación la propuesta académica de la UARTES se basa en un marco conceptual "en el que confluyen la interpelación socio-cultural profunda de los procesos de colonialismo y neocolonialismo y la construcción de un modelo alternativo al desarrollo, (y se guía) por seis grandes ejes: 1) decolonialidad, 2) interculturalidad, 3) derechos culturales, 4) transdisciplinariedad, 5) soberanía, 6) inter-aprendizaje”. Esa propuesta, que claramente explicita la voluntad gubernamental de configurar un nuevo modelo de desarrollo, hay que escudriñar atendiendo a lo que de la opción decolonial retienen "los llamados príncipes del pensamiento correista. Situados estratégicamente en sectores que tienen que ver con el desarrollo del conocimiento, la investigación y la ciencia, que se expresan en exuberantes documentos publicados por sus correspondientes ministerios y el IAEN"21. Es uno de esos príncipes, René Ramírez, quien en agosto de 2013 presentó las cuatro universidades emblemáticas como el "pretexto simbólico para un pacto nacional para la construcción de la sociedad del conocimiento, la creatividad y la excelencia". Y a la UARTES como el "proyecto insignia en el país del arte y la cultura cuya apertura esperan miles de

20. Universidad de las Artes del Ecuador. Un proyecto de la Revolución Cultural. Resumen Ejecutivo del Proyecto (2013). Hasta que no indique lo contrario los entrecomillados remiten a este documento.

21. Ecuador: análisis de coyuntura y nuevos escenarios políticos en el horizonte. Decio Machado 26.02.2014. http://www.deciomachado.blogspot.com. El IAEN es el Instituto de Altos Estudios Nacionales, Universidad de Postgrado del Estado de Ecuador (23), http://www. educacionsuperior.gob.ec [consultado el 14 de agosto de 2013] 
ecuatorianos para la profesionalización en una gama amplia de carreras relacionadas con las industrias culturales como la cinematografía y las artes, como las plásticas, las escénicas o las musicales". Las industrias culturales son pues el horizonte de la UARTES, algo que anticipó el I Encuentro Sur-Sur. Geopolíticas, artes y creatividades. Para el Buen Vivir y la Transformación Social celebrado en la UASB. Explicaba su organizadora Mayra Estévez, a la sazón subsecretaria de arte y creatividad del Ministerio de Cultura, que el objetivo del encuentro ${ }^{22}$ era "promover la construcción de políticas públicas para las artes y las creatividades a través de una metodología participativa y de diálogo intercultural, a fin de consolidar el desarrollo de los estudios culturales, la formación, la promoción, la libre promoción de las prácticas artísticas y manifestaciones culturales y creativas". Todo un programa que no olvida aludir a los estudios culturales y apuesta por su consolidación.

\section{MISTIFICACIONES QUE PERDURAN: ¿UNA UARTES DECOLONIAL?}

"Lourdes: „He aquí el acontecimiento que tanto esperabas; Al fin se inaugura la universidad que fusionará (en esta época de fusiones) las artes literarias interculturales con el Sumak Kawsay. Aunque con temor veo que los encargados de inaugurarla son los mismos (actores) de siempre". Cuando el 11 de febrero de 2014 recibí este correo electrónico reaccioné con estupefacción. Me lo enviaba un informante entrevistado en 2012 y al que volví a ver en Quito a finales de noviembre 2013. Durante ese encuentro le conté que durante mi reciente estancia en Guayaquil, en el edificio de la Gobernación, una de las sedes de la UARTES, sólo había encontrado una banderola anunciando: "Aquí será el campus inicial de la Universidad de las Artes", algunos obreros trabajando, varios guardias de seguridad, y un folio pegado con cello en una puerta que remitía a la Oficina de Turismo a quien quisiera información sobre la UARTES. Le expliqué, mientras que él reía, que cuando pedí en la Oficina de Turismo la malla curricular (plan de estudios) de artes visuales quien me atendió, tras ensalzar las iniciativas del gobierno, me dijo que no había. "Pero es porque todavía no empiezan. Vaya usted mirando en la página web de la Universidad, seguro que cuando la tengan figurarán". Esa misma persona, tras preguntarme mi profesión, me dijo que ella sabía que andaban "reclutando maestros cualificados" y que me animara a postular ya que el Presidente Correa había dicho en televisión que "todos serían bienvenidos".

El correo recibido me intrigó tanto que recurrí a Youtube a sabiendas de la importancia que la imagen tiene para el gobierno de Correa, y del control que éste ejerce sobre los

22. Celebrado del 28 al 30 de enero de 2013. En una entrevista a El Telégrafo (21.01. 2013) señalaba Estévez que esperaban contar con el Secretario Nacional de Planificación y Desarrollo, para que hiciera "el ejercicio de traducir estos procesos de pensar la planificación del país, también en clave de prácticas que puedan sostener el ámbito de las artes pensando en economías creativas". 
medios de comunicación. Dos saberes adquiridos y constatados durante mis estancias en Ecuador. Además, si nos atenemos a los datos barajados por la Sociedad Interamericana de Prensa, tanto el control de los medios de comunicación como la censura se habrían incrementado notablemente desde 2014. Tal y como suponía, no tuve la menor dificultad en encontrar el vídeo de la inauguración ${ }^{23}$ llamándome varias cosas la atención: 1) la cámara nunca enfocaba al público que aplaudía las palabras de Correa, y 2) el vídeo sólo mostraba la fachada del edificio de la Gobernación, la maqueta del proyecto global que de llevarse a cabo renovará el centro de Guayaquil, y un aula con ordenadores. Esas imágenes difundidas por diversos canales televisivos no pueden leerse en meros términos publicitarios sino que remiten, tal y como señala Quijano, al creciente uso de todo tipo de imágenes para, entre otros objetivos, producir una legitimación de las ideología y una mistificación de la experiencia. Aunque coincido en el análisis, no sé si esa tendencia es "una de las diez centrales en el proceso de completa reconfiguración de la Colonialidad Global del Poder, del patrón de poder hegemónico en el planeta" (Quijano, 2011: 83). En esta inauguración es de destacar su función de cara a la legitimación de la ideología y la mistificación de la experiencia, y el ejercicio de oportunismo político que supuso al celebrarse doce días antes de las elecciones seccionales (municipales) lo que no evitó que el partido de Correa perdiera, entre otras ciudades, Quito, Manta, Portoviejo, Loja, Cuenca o la propia Guayaquil. A la vacuidad de los comentarios del Ministro de Cultura Paco Velasco mientras mostraba ante las cámaras la maqueta de la UARTES, hay que añadirle la de un Presidente que la rellenaba con datos estadísticos sobre la procedencia, edades y sexo de los/as 224 estudiantes inscritos en los tres programas que se iniciarían en septiembre de 2014. Con su habitual entusiasmo anunció Correa que se procedería a la titulación "por experiencia y por trayectoria, de muchos artistas ecuatorianos a los que se reconocerá con un título de tercer nivel", que así accederían a "un título académico y a derechos y posibilidades de empleo y seguro de jubilación". También insistió en que se inauguraba "la Universidad de las Artes y de la economía social del conocimiento", recordando que Ecuador había gastado más de "mil millones de dólares en la creación de cuatro nuevas universidades de vanguardia de nivel mundial". Inaugurada quedó y cualquier estudiante que dispusiera de conexión a internet podía descargarse el folleto a todo color de la UARTES, bilingüe español/inglés.

Más de medio año después de su inauguración la UARTES no pudo proporcionar a su alumnado la malla curricular de los estudios en Artes Literarias Interculturales. Estudios que tendrían como objetivo "formar investigadores de literatura nacional y regional. (A los que) se capacitará en técnicas de recopilación, estudio de campo y edición literaria. La idea es que sistematicen y documenten la literatura oral urbana y rural del Ecuador $y$

23. Presidente Correa inaugura la Universidad de las Artes. Video subido a Youtube.com por la Gobernación del Guayas. 12.02.2014. Duración: 6’ 59” 
Latinoamérica. En la carrera, que toma 4 años, los alumnos estudiarán quichua y shuar"24. Un objetivo que no parece especialmente orientado por la ansiada decolonialidad. Y, sin embargo, quien a finales de 2015 acceda a la renovada página web de la UARTES leerá que la decolonialidad "implica la toma de conciencia de los procesos de colonialidad del ser, del poder, del saber $y$ del ver y propone respuestas y soluciones alternativas y propias frente a las corrientes dominantes de las matrices hegemónicas, valorando y visibilizando a la diversidad de conocimientos y saberes tradicionales y contemporáneos, así como su capacidad holística e integradora". Una declaración de intenciones que no se plasma en las mallas curriculares accesibles desde diciembre de 2015. Pero hay más. Si el añadido de la "colonialidad del ver" probablemente responda a la difusión de una estética decolonial que seguía abriéndose camino, siempre desde el programa de doctorado en estudios culturales de la UASB, que a finales de junio de 2014 organizó el encuentro internacional Estética, política, miradas decoloniales... en el que, como diría mi informante, participaron los mismos actores de siempre; ¿a qué responde la metamorfosis de los estudios en Artes Literarias Interculturales en una licenciatura en Literatura con cinco itinerarios, entre ellos uno en Lengua y Literatura Kichwa/Shuar? Además, al menos si tenemos en cuenta la voluntad de acabar con todo tipo de colonialidad, lo más llamativo es que los planes de la UARTES podrían existir en Duke University, o en la Universidad de Sevilla. Materias compartidas por las cuatro licenciaturas como las de Historia y teoría de las artes (I, II, III); Fundamentos de Estética, Sociología y Filosofía del Arte; Nuevos medios: prácticas y perspectivas críticas; y otras sólo presentes en artes visuales como la hoy tan de moda Antropología Visual, corroboran lo que un grupito de estudiantes de la UARTES me contaba en noviembre de 2014. Me dijeron, hablando de los en aquel momento inexistentes planes de estudio, "las autoridades están teniendo muchos problemas porque los están haciendo gente de fuera, dicen que un francés, y alguien de Alemania, y entonces...vienen algunos profesores, $y$ dan alguna conferencia y...". Una realidad conocida y potenciada por el gobierno de Correa y, dentro de él, por quien desde abril de 2015 es el séptimo Ministro de Cultura y que hasta entonces encabezaba el Ministerio Coordinador de Conocimiento y Talento Humano: Guillaume Long. Desde ese cargo reconocía Long su viaje a Alemania para contactar con la mayor Universidad de las Artes del mundo y hablarles de la UARTES, y también que había en Ecuador unos mil Prometeos, distribuidos en 30 universidades y 20 institutos de investigación contratados para liderar investigaciones y dar clases y, más importante aún, señalaba que la UARTES era la prueba de que el gobierno no sólo creía en el desarrollo, sino también "en el buen vivir y eso implica arte, cultura, creatividad, [...] sabemos que una sociedad con pensamiento crítico le va a dar profundidad a la democracia, todos estos elementos son

24. El Reto Académico de la Universidad de las Artes, El Comercio.com (06.01.2014). Declaraciones de Alicia Ortega, Ph.D por la Universidad de Pittsburg, profesora de la UASB vinculada al doctorado en estudios culturales, y consultora para el diseño de los estudios de Artes Literarias Interculturales. 
importantes y a nivel económico las industrias culturales en ciertos países juegan un rol muy importante, fíjate que en Estados Unidos el 12\% del PIB (Producto Interno Bruto) son industrias culturales" 25 . En este extracto puede constatarse cómo Long articula el buen vivir al arte y a la cultura recuperando así los ejes de la política cultural propuesta por Erika Silva para pasar, sin transición alguna, al pensamiento crítico, la democracia y las industrias culturales. Y lo hace de la mano del proyecto de una UARTES que actualmente, desde su cargo de Ministro de Cultura, está bajo su responsabilidad. Quizás su objetivo consista en lograr que la UARTES tome el camino indicado por un René Ramírez que, un año después de su inauguración, afirmaba durante su visita al Instituto Superior Tecnológico de Artes del Ecuador (ITAE), ubicado también en Guayaquil y llamado a articularse de algún modo con la UARTES, que el arte era "una opción pertinente para el cambio de la matriz productiva del Ecuador"26.

\section{CONCLUSIÓN}

Complejo campo de batalla ideológico, el diseño de toda política cultural moviliza ideales culturales, políticos, económicos y estéticos (Carvajal, 2010), y afecta a las comunidades y/o colectivos que luchan por ver reconocidos sus derechos en el seno de los estados. Aunque ese campo de batalla ideológico no se limita al de la política cultural en él adquiere dimensiones particulares porque, a través de ella, un Estado como el ecuatoriano cuya Constitución declara intercultural y plurinacional, y también (no lo olvidemos) unitario, "da cancha", por utilizar el término empleado por dos informantes mestizas urbanas de Quito, a que se exprese la diversidad (étnico-cultural, patrimonial, artística, u otra) de sus sujetos (individuales y/o colectivos). El problema reside en que ese "dar cancha", a la par que permite la expresión pública de las diversidades, oculta que "diversidad cultural" e "interculturalidad" no son sinónimas y que el reto para alcanzar esta última es político, es de derechos, y no meramente expresivo. La estetización y folclorización de cuestiones candentes como las de la interculturalidad o, a otro nivel, la de la decolonialidad del saber, forman parte de un escenario de 'posmodernidad celebratoria' siendo dos estrategias que contribuyen a desactivarlas justo cuando, dado el avance del neoliberalismo en los estados post-neoliberales, más urge reactivarlas políticamente. Conscientes de esa urgencia, y de los efectos de la folclorización, durante la Cumbre de los Pueblos Indígenas convocada por ECUARUNARI y CONAIE que tuvo lugar en Quito en marzo de 2015, se denunció que las culturas indígenas ocupaban "un papel subalterno en la apreciación cultural del país. [...] Que a las culturas indígenas se las definen como "folklore" y que 25. "Guillaume Long, hablando de lo humano y lo divino en educación". revistazonalibre.com (acceso 15.11.2015).

26. Boletín de Prensa no 34 de 11 de febrero de 2015 de la Secretaría de Educación Superior, Ciencia, Tecnología e Innovación de Ecuador. 
no se aprecian debidamente. Que entonces no se puede hablar de interculturalidad"27. En efecto, cuando "culturales" sólo son los indígenas, cuando sus culturas son las únicas susceptibles de ser folclorizadas, la interculturalidad sigue siendo un objetivo político que no se ha alcanzado.

A lo largo de estas páginas, confrontando discursos políticos y académicos en los que son centrales las referencias a la decolonialidad, la interculturalidad y el Sumak Kawsay, con realidades empíricas como la de la reestructuración universitaria en Ecuador y la creación de la UARTES, he querido llamar la atención sobre cómo el uso retórico de dichas nociones encubre las políticas neoliberales desde las que el gobierno de la revolución ciudadana está reestructurando todos los campos de actividad, incluidos los del arte y de la cultura. Y, más importante si cabe, he querido indicar cómo ese uso se incrementa a medida que dichas políticas avanzan lo que permite llevarlas a cabo sin que, al menos durante un cierto tiempo, exista ante ellas una oposición capaz de denunciar las promesas incumplidas y de organizarse para que éstas se hagan realidad. Y, cuando eso empieza a suceder, aumenta la represión de quienes osan levantar la voz y recordar el foso que separa realidad y discurso. Así, el cierre de la Amawtay Wasi muestra la fragilidad política en la que se encuentran sumidas las organizaciones indígenas en Ecuador. Y si lo analizamos a partir de las posiciones de autores indígenas con $\mathrm{PhD}$, como Macas o Muyolema entre otros, que asumen las tesis sobre la colonialidad del poder y del saber, comprendemos que este último lo considere como un epistemicidio. Y también que considere que se está produciendo un "uso y abuso [...] de conceptos como el Sumak Kawsay ilustrativo de una práctica política mucho más profunda de extractivismo simbólico y suplantación política" (Muyolema, 2015: 15). Para este autor, profesor en la Universidad de Wisconsin, el correismo sería una estructura emergente de poder fáctico que genera "imaginarios que reproducen una forma de gestión vertical y autoritaria en todos los niveles de la administración pública, basados en los discursos de la eficiencia, de los resultados ("gobierno de resultados" dicen las páginas oficiales) y en el poder mágico del eslogan: "el buen vivir", "el cambio de época", "el cambio de matriz productiva" o "el predominio del ser humano sobre el capital", repetidos hasta el cansancio en la prensa "pública" al servicio del gobierno" (Muyolema, 2015: 17- nota 2). Como hemos visto son esas nociones, a las que habría que añadir la de decolonialidad, las privilegiadas por el gobierno de Ecuador para ocultar, tras una retórica emancipadora, sus apuestas neoliberales.

Para ahondar en la complejidad del campo del arte y de la cultura de Ecuador, y en los efectos sobre dicho campo de una reflexividad institucional constatables en la

27. Correo electrónico enviado el 8 de marzo de 2015 por Ileana Almeida, miembro del Proyecto $\mathrm{I}+\mathrm{D}+\mathrm{i}$ (2012-2014) "Impactos del reconocimiento de la interculturalidad y la plurinacionalidad en los sistemas educativo, cultural y de salud de Ecuador”, al director del mismo. 
progresiva emergencia y circulación académica y político-institucional de nociones como la de decolonialidad, habría que apostar por un quehacer antropológico basado en una práctica etnográfica más acorde con la llevada a cabo por Clastres, que con las rutas emprendidas por Clifford. Esa apuesta, que defiendo, requiere una seria reflexión sobre la disciplina antropológica y plantearse, colectivamente, si puede construirse -y cómo-una antropología decolonial teniendo en cuenta el contenido de la noción, sus consecuencias epistemológicas, y sus posibles efectos sobre la práctica etnográfica. El reto no es "in-disciplinar", sino "re-disciplinar" la antropología para que ésta siga elaborando conocimientos críticamente fundamentados que resistan la prueba de fuego de su confrontación con lo empírico. 


\section{REFERENCIAS BIBLIOGRÁFICAS}

Anzaldúa, Gloria (1987) Borderlans/La Frontera. The New Mestiza. San Francisco: Aunt Lute Books.

Arcos-Palma, Ricardo (2010) "Decolonialidad vs. Altermodernidad: ¿dos Posturas Irreconciliables??. Esfera Pública, www.esferapublica.org [consultado el 15 de noviembre de 2014].

Bourdieu, Pierre y Wacquant, Loïc (2001) Las argucias de la razón imperialista. Barcelona: Paidós.

Bretón, V.; Cortez, D.; García, F. (2014) "En busca del Sumak Kawsay. Presentación del dossier". Iconos, 48, pp.9-24.

Carballo, Francisco y Mignolo, Walter (2014) Una concepción descolonial del mundo. Buenos Aires: Ediciones del Signo and Globalization and Humanities Project (Duke University).

Carvajal, Iván (2010): "Notas sobre 'política cultural" ". Ecuador Debate, 81, pp. 51-62.

Castro-Gómez, Santiago (2007) "Decolonizar la universidad. La hybris del punto cero y el diálogo de saberes”. En Santiago Castro-Gómez y Ramón Grosofoguel (eds), El giro decolonial. Reflexión para una diversidad epistémica más allá del capitalismo global. Bogotá: Siglo del Hombre, Universidad Central, Pontificia Universidad Javeriana, pp. 79-91.

Castro-Gómez, Santiago (2012) “Entrevista”. Tabula Rasa, 16, pp. 213-230.

De Salvador, Saleta y Martínez, Yolanda (2015) "Apropiaciones comunitarias en los indígenas shuar”. Revista Internacional de Comunicación y Desarrollo, 1, pp. 41-49.

Estermann, Josef (2014) "Colonialidad, descolonización e interculturalidad. Apuntes desde la filosofía intercultural”. Polis, 38, http:// polis.revues.org, publicado el 08 de septiembre de 2014 [consultado el 17 de noviembre de 2015].

Fanon, Franz (1961) Les damnés de la terre. Paris: Maspero.

Geertz, Clifford (1999) "Dos visiones de la antropología”. Revista de Occidente, 222, pp. 136-151.

Gough, Kathleen (1975) [1968] "Des propositions nouvelles pour les anthropologues". En Jean Copans (ed.), Anthropologie et impérialisme. Paris: Maspero, pp. 17-59.

Garbe, Sebastián (2012) "Descolonizar la antropología, antropologizar la Colonialidad". Otros Logos. Revista de Estudios Críticos, pp. 114-129.

Grosfoguel, Ramon (2013) “Entrevista”. Metapolítica, 17 (83), pp. 38-49. 
Laclau, Ernesto (2005) La razón populista. México: Fondo de Cultura Económica.

Lins-Ribeiro, Gustavo (2011) "La antropología como cosmopolita: globalizar la antropología hoy”. En Alejandro Grimson, Silvina Merenson, Gabriel Noel (comps), Antropología Ahora. Buenos Aires: Siglo XXI, pp. 69-96.

Macas, Luís (2005) "La necesidad política de una reconstrucción epistémica de los saberes ancestrales". En Pablo Dávalos (comp.) Pueblos Indígenas, Estado y Democracia. Buenos Aires: CLACSO, pp. 35-42.

Martínez Novo, Carmen (2009) "La crisis del proyecto cultural del movimiento indígena". En Carmen Martínez Novo (ed.) Repensando los movimientos indígenas. Quito: FLACSO/ Ministerio de Cultura, pp. 173-196.

Martínez Novo, Carmen (2014) "Managing Diversity in Postneoliberal Ecuador". The Journal of Latin American and Caribbean Anthropology, vol. 19(1), pp. 103-125.

Mignolo, Walter (2008) "La opción de-colonial: desprendimiento y apertura. Un manifiesto y un caso". Tabula Rasa, 8, pp. 243-281.

Mignolo, Walter y Gómez, Pedro Pablo (2012) Estéticas decoloniales. Bogotá: UFD.

Méndez, Lourdes (2005) "Una connivencia implícita: 'perspectiva de género', 'empoderamiento' y feminismo institucional'. En Rosa Andrieu y Carmen Mozo, (coords.) Antropología feminista y/o del Género. Legitimidad, poder y usos políticos. Sevilla, El Monte, FAAEE/AAA, pp. 203-226.

Moreira, Darío (1977) La política cultural en Ecuador. UNESCO: Colección Políticas culturales: estudios y documentos.

Muyolema, Armando (2015) "La CONAIE en el ojo del huracán del correismo". alter/ nativas, 4, pp. 1-15.

Quintero, Pablo y Petz, Ivanna (2009) "Refractando la modernidad desde la colonialidad. Sobre la configuración de un locus epistémico desde la geopolítica del conocimiento y la diferencia colonial". Gazeta de Antropología, 25(2), artículo 52. http://hdl.handle.net

Quijano, Anibal (1992) “Colonialidad y modernidad/racionalidad”. En H. Bonilla (comp.) Los conquistados. 1492 y la población indígena de las Américas. Quito: Libri Mundi.

Quijano, Anibal (2000) “Colonialidad del poder y clasificación social”. Journal of WorldSystem Research, vol. XI, 2, pp. 342-386.

Quijano, Anibal (2011) “Bien vivir': entre el 'desarrollo' y la des/colonialidad del poder”. Ecuador Debate, 84, pp. 77-88.

Ramos, Alcida Rita (2011) "Por una antropología ecuménica". En Alejandro Grimson, Silvina Merenson, Gabriel Noel (comps), Antropología Ahora. Buenos Aires: Siglo XXI, pp. $97-124$. 
Rivera Cusicanqui, Silvia (2010) Chiixinakax utxiwa. Una reflexión sobre prácticas y discursos descolonizadores. Buenos Aires: Tinta Limón.

Sousa Santos, Boaventura de (2008) Conocer desde el Sur: Para una cultura política emancipatoria. La Paz: CIDES-UMSA/CLACSO/Plural.

Villavicencio, Arturo (2013) “¿Hacia dónde va el proyecto universitario de la revolución ciudadana?”. La línea de fuego. [http://lalineadefuego.info/2013/05/01]

Walsh, C.; Schiwy, F.; Castro-Gómez, S. (comps.) (2002) Indisciplinar las Ciencias Sociales: Geopolíticas del conocimiento y colonialidad del poder. Perspectivas desde lo Andino. Quito: Abya Yala.

Walsh, Catherine (2003) “QQué saber, qué hacer y cómo ver? Los desafíos y predicamentos disciplinares, políticos y éticos de los estudios (inter) culturales desde América andina”. En Catherine Walsh (ed.) Estudios culturales latinoamericanos. Retos desde y sobre la Región Andina. Quito: UASB/ Abya Yala, pp. 11-28.

Walsh, Catherine (2008) "Interculturalidad, plurinacionalidad, decolonialidad: las insurgencias político-epistémicas de refundar el Estado". Tabula Rasa, 9, pp. 131-152. 